\title{
THE INCIDENCE AND PATTERNS OF ILLNESS AT THE SOCHI 2014 WINTER PARALYMPIC GAMES: A PROSPECTIVE COHORT STUDY OF 6564 ATHLETE DAYS
}

Derman, W. (Prof) Institute of Sport and Exercise Medicine, Department of Surgery, Stellenbosch University, International Olympic Committee (IOC) Research Centre. Faculty of Health Sciences, University of Cape Town. ewderman@iafrica.com

Schwellnus, M. P. (Prof). Institute for Sport, Exercise Medicine and Lifestyle Research, Faculty of Health Sciences, University of Pretoria; International Olympic Committee (IOC) Research Centre; Emeritus Professor, Faculty of Health Sciences, University of Cape Town. mschwell@iafrica.com

Jordaan, E. Biostatistics Unit, Medical Research Council of South Africa, Statistics and Population Studies Department, University of the Western Cape. esme.jordaan@mrc.ac.za

Runciman, P. (Dr). Institute of Sport and Exercise Medicine, Department of Surgery, Stellenbosch University. phoebe.runciman@gmail.com

Van de Vliet, P. (Dr) Medical \& Scientific Department, International Paralympic Committee, Bonn, Germany. peter.vandevliet@paralympic.org

Blauwet, C. Department of Physical Medicine and Rehabilitation, Spaulding Rehabilitation Hospital and Brigham and Women's Hospital, Harvard Medical School, Boston, USA. cblauwet@gmail.com

Webborn, N. (Prof) Centre for Sport and Exercise Science and Medicine (SESAME), University of Brighton, UK. nickwebborn@sportswise.org.uk

Willick, S. (Prof) Physical Medicine and Rehabilitation, University of Utah Orthopaedic Center.stuart.willick@hsc.utah.edu 
Stomphorst, J. Department of Sport Medicine. Isala Klinieken, Zwolle, Netherlands. jstomphorst@hotmail.com

"The corresponding author has the right to grant on behalf of all authors and does grant on behalf of all authors, an exclusive licence (or non exclusive for government employees) on a worldwide basis to the BMJ Publishing Group Ltd and its licensees to permit this article (if accepted) to be published in Journal (British Journal of Sports Medicine) editions and any other BMJPGL products to exploit all subsidiary rights, as set out in our license."

\section{Address for correspondence}

Professor Wayne Derman

Institute of Sport and Exercise Medicine

Division of Orthopaedic Surgery

Faculty of Medicine and Health Science

Room 4019, $4^{\text {th }}$ Floor, Clinical Building

Tygerberg Medical Campus

Francie van Zijl Drive, Bellville, Cape Town, 7505

\section{Keywords}

Paralympic, impairment, disability, illness, international sporting events, athletes

\section{What are the new findings?}

- This was the first study to document incidence of illness at a Winter Paralympic Games per 1000 athlete days

- There was a higher incidence of illness at the Sochi 2014 Winter Paralympic Games, compared to the 2012 London Summer Paralympic Games and Sochi 2014 Winter Olympic Games

- There was a similar incidence of illness in all sporting categories

- Illnesses in the respiratory system, eye and adnexa and digestive system were most common

How might this impact on clinical practice in the near future? 
- The information in the present study can be used by organisations, coaches and athletes to identify physiological systems at risk for illness in a Winter Games setting for athletes with impairment

- The identification of areas of risk provides the basis for illness prevention programs at the athlete level, as well as the organisational level

- This study has provided a repeatable methodology for the capturing and analysis of the incidence of illness in athletes with impairment in a Winter Paralympic Games setting, providing the basis for future studies at upcoming Paralympic Games

\section{Contributorship: None}

Funding: IOC Research Centre (South Africa) Grant, IPC Research Grant 


\section{ABSTRACT}

Objective: To describe the epidemiology of illness at the Sochi 2014 Winter Paralympic Games.

Methods: A total of 547 athletes from 45 countries were monitored daily for 12 days over the Sochi 2014 Winter Paralympic Games (6564 athlete days). Illness data were obtained daily from teams without their own medical support (13 teams, 37 athletes) and teams with their own medical support (32 teams, 510 athletes) through electronic data capturing systems.

Results: The total number of illnesses reported was 123, with an illness incidence rate (IR) of 18.7 per 1000 athlete days (95\% CI 15.1\% - 23.2\%). The highest IR was reported for wheelchair curling (IR of 20.0 (95\% CI 10.1\% - 39.6\%)). Illnesses in the respiratory system (IR of 5.6 (95\% CI 3.8\% - 8.0\%)), eye and adnexa (IR of 2.7 (95\% CI 1.7\% - 4.4\%)) and digestive system (IR of $2.4(95 \%$ CI 1.4\% - 4.2\%)) were the most common. Older athletes ( 35 - 63 years) had significantly higher IR than younger athletes $(14-25$ years, $p=0.049)$.

Conclusion: The results of the current study indicate that Paralympic athletes report higher illness incidence rates compared to Olympic athletes at similar competitions. The highest rates of illness were reported for the respiratory, eye and adnexa and digestive systems, respectively. Thus, the results of this study forms a basis for the identification of physiological systems at higher risk of illness, which can in turn inform illness prevention and management programs with eventual policy change to promote athlete safety in future editions of the Winter Paralympic Games. 


\section{INTRODUCTION}

Illness has rarely been studied in major sporting events in athletes with impairment. Reference to illness in early studies of injury in Paralympic athletes suffered from the use of a generic illness definition.[1-5] There was also inconsistency in the definition of illness across studies.

Illness was reported during pre-competition and competition periods of the London 2012 Summer Paralympic Games.[6] The illness incidence rate (IR) was 13.2 illnesses per 1000 athlete days in a cohort of 3565 athletes. The highest IR was in the respiratory system (IR of $3.6(95 \% \mathrm{CI})$ ), followed by the skin (IR of 2.40 (95\% CI)), digestive (IR of $1.90(95 \% \mathrm{CI})$ ), nervous (IR of $1.26(95 \% \mathrm{CI})$ ) and genitourinary (IR of $1.12(95 \% \mathrm{CI}))$ systems. The IR was highest in the sports of equestrian (IR of 20.7 (95\% CI)), powerlifting (IR of $15.8(95 \% \mathrm{CI})$ ) and athletics (IR of $15.4(95 \% \mathrm{CI})$ ). Age and sex were not independent predictors of illness. The overall illness incidence rate as well as proportion of athletes with an illness was higher compared to data from studies conducted in similar able-bodied athlete populations.[7-9] This study concluded that a population of athletes with impairment might be more vulnerable to illness by nature of their underlying impairment. $[10,11]$

The International Paralympic Committee (IPC) adopted a Medical Code in 2011 which "encourages all stakeholders to ensure that sport is practiced in a manner that protects the health of the athlete and minimises the chance of injury and illness...".[12] To do so, the IPC Medical Committee has implemented a long-term prospective illness surveillance project to characterize the risk factors for illness at major events, commencing at the London 2012 Paralympic Games. No such study has ever been conducted in a Paralympic Winter sports environment.

The aim of our study was to document illness at the Sochi 2014 Winter Paralympic Games, using the same web-based injury and illness surveillance system (WEB-IISS) utilised at the 2012 London Paralympic Games.[13] Overall illness incidence rate, illness incidence rate per sport, type of illness and physiological systems affected by the illness were investigated for the 12 days of the Games period.

\section{METHODS}


The present study was a component of a larger ongoing epidemiological study of both Summer and Winter Paralympic Games. This prospective component of the epidemiology of illness was conducted during the three day pre-competition period and nine day competition period of the Sochi 2014 Winter Paralympic Games. For the purpose of this study, the precompetition period and competition period were combined and analysed as one 12-day Games period.

\section{Participants}

The current study was conducted through the IPC Medical Committee. Before research activities were conducted, ethical approval for this study was granted by both the University of Brighton (FREGC/ES/12/11) and the University of Cape Town (HREC/REF 436/2012) Research Ethics Committees. Informed consent was obtained from all athletes for the use of de-identified medical data gathered during the Games.

We utilised the web-based injury and illness surveillance system (WEB-IISS) which was successfully implemented at the London 2012 Paralympic Games. The WEB-IISS was utilised for data collection by teams with their own medical support staff. For athletes who did not have accompanying medical staff, illness data were captured via the ATOS information system (Bezons, France) supplied to the medical staff employed by the Sochi Organising Committees of the Olympic and Paralympic Games (SOCOG). Complete details of data sources, data collection methodology, data input and analysis can be found in the previous literature.[13] Specific fields were adapted within the WEB-IISS with regard to Winter sports, which included certain aspects of each athlete's classification within the sports they competed in (lower limb impairment, minimally impaired, sitting class, standing class and visual impairment) as well as the factors contributing to illness.

In brief, introductory information about the study was sent via email to all National Paralympic Committees (NPC) and Chief Medical Officers (CMO) of the teams participating at the Sochi 2014 Winter Paralympic Games. Detailed information regarding the study was provided to the team physicians of all delegations, as well as medical members of the Paralympic Village polyclinic (for countries who did not have their own medical staff), at the pre-competition medical briefing on day 2 of the pre-competition period. Participation and compliance from teams with medical staff was incentivised by the provision of a data entry 
tablet to each participating country that had more than 10 athletes competing at the Games. The remainder of the countries with accompanying medical staff reported their data via laptop computers. The data of athletes who did not have accompanying medical staff were captured via the ATOS data capturing system supplied to the polyclinic doctors of the Sochi Organising Committees of the Olympic and Paralympic Games (SOCOG).

\section{Definition of illness}

A general definition accepted for reporting illness was defined as any athlete requiring medical attention, regardless of the consequences with respect to absence from competition or training. A medical illness was specifically defined as "any newly acquired illness as well as exacerbations of pre-existing illness that occurred during training and/or competition or during or immediately before the Sochi 2014 Winter Paralympic Games”.[13]

\section{Calculation of athlete days}

\section{Teams without their own medical support}

The exposure data in terms of athlete days for countries without their own medical support was made on the assumption that the total number of athletes, as published in the IPC athlete database, was static for the duration of the Games. The total athlete days were calculated as follows: total term days (pre-competition and competition 12 day period) $\mathrm{x}$ daily team size (for each day).

\section{Teams with their own medical support}

The CMO of each team was requested to capture their daily team size (number of athletes that were under the care of the medical team), and register any new illness. An analysis of the data of teams with their own medical support (WEB-IISS) showed that there was a negligible variance $(\sim 0.5 \%)$ between reported number of athletes in each delegation and the total number of athletes, as published in the IPC athlete database. Therefore, total athlete days for each country was also calculated as described for teams without their own medical support.

\section{Calculation of illness incidence rate and illness proportion}

The illness incidence rate (IR) was calculated as illnesses per 1000 athlete days. The number of athlete days were reported separately by sporting categories, age group and sex. The IR per 1000 athlete days was reported for all illnesses, as well as illnesses in different sports and 
physiological systems. The illness proportion refers to the percentage of athletes reporting an illness during the study period and was calculated as the number of athletes with an illness over the total number of athletes competing in the relevant sub group.

\section{Statistical analysis of the data}

Data were in the form of counts (i.e. the number of illnesses each athlete reported). Athletes could participate in more than one sport and/or more than one event. Some athletes incurred multiple illnesses during the 12 days, thus the outcome variable was the number of illnesses each athlete reported. Standard descriptive statistical analyses were reported, including number of athletes participating in the various sports (combining alpine skiing with snowboarding and cross country skiing with biathlon) by age (14-25 years, 26-34 years and 35-63 years) and sex (male or female), number of reported illnesses, number and proportion of athletes with an illness. Generalized linear Poisson regression modelling was used to model the number of reported illnesses overall, as well as the number of illnesses for physiological systems affected by the illness, and were corrected for overdispersion and including the independent variables of interest. Results were reported as illness incidence rates per 1000 athlete days (including 95\% confidence intervals). Results for overall illness rates were reported by sex, age group and type of sport.

\section{RESULTS}

\section{Participants}

All countries chose to participate in the study. During the Games period, a total of 45 NPCs, representing 547 athletes over 6564 athlete days were monitored. Teams with their own medical support staff comprised a total of 6096 athlete days (32 countries, 508 athletes), whilst teams without medical support staff comprised a total of 468 athlete days (13 countries, 39 athletes).

There were $418(76 \%)$ male and 129 (24\%) female athletes in the study. The mean ( + SD) age of all athletes in this study was $31.2 \pm 9.5$ years $($ minimum $=14$ years and maximum $=63$ years). Total numbers of athletes, as well as sex and age distribution in each sport is presented in Table 1. 


\begin{tabular}{lllllll}
\hline Sport & All athletes & Males & Females & Age 14-25 & Age 26-34 & Age 35-63 \\
\hline All & 547 & 418 & 129 & 172 & 198 & 177 \\
Alpine skiing/snowboarding & 219 & 163 & 56 & 75 & 88 & 56 \\
Cross country skiing/biathlon & 149 & 95 & 54 & 60 & 49 & 40 \\
Ice sledge hockey & 129 & 129 & 0 & 34 & 53 & 42 \\
Wheelchair curling & 50 & 31 & 19 & 3 & 8 & 39 \\
\hline
\end{tabular}

\section{Incidence of illness by sport}

Table 2 presents the total number of illnesses as well as illnesses reported in four categories of sports during the combined pre-competition and competition periods. The total number of illnesses recorded in all sports was 123 illnesses in 95 athletes (17.4\% of all athletes), with an IR of 18.7 per 1000 athlete days (95\% CI 15.1\% - 23.2\%). The incidence of illness was similar across all four sporting categories. The combined sports of alpine skiing/snowboarding contained the highest total number of illnesses (51 illnesses in 41 athletes), however the highest IR of 20.0 per 1000 athlete days was reported in wheelchair curling $(95 \%$ CI $10.1 \%$ - 39.6\%). An IR of 19.4 was reported in both the alpine skiing/snowboarding sports as well as ice sledge hockey (95\% CI 13.9\% - 27.0\% for alpine skiing/snowboarding; 95\% CI 12.6\% - 29.9\% for ice sledge hockey), whilst an IR of 16.8 $(95 \%$ CI $10.9 \%-25.9 \%)$ was reported in the Nordic events of cross country skiing/biathlon.

Table 2: Incidence of illness by sport (total number of illnesses, number of athletes with an illness, total number of athletes competing, total number of athlete days, proportion of athletes with an illness, illness incidence rates per athlete days)

\begin{tabular}{|c|c|c|c|c|c|c|}
\hline Sport & $\begin{array}{l}\text { Total } \\
\text { number } \\
\text { of } \\
\text { illnesses }\end{array}$ & $\begin{array}{l}\text { Number } \\
\text { of athletes } \\
\text { with an } \\
\text { illness }\end{array}$ & $\begin{array}{l}\text { Total } \\
\text { number of } \\
\text { athletes } \\
\text { competing }\end{array}$ & $\begin{array}{l}\text { Total } \\
\text { number of } \\
\text { athlete } \\
\text { days }\end{array}$ & $\begin{array}{l}\text { Proportion } \\
\text { of athletes } \\
\text { with an } \\
\text { illness }\end{array}$ & $\begin{array}{l}\text { Illness incidence } \\
\text { rate } \\
\text { illnesses/1000 } \\
\text { athlete days } \\
(95 \% \mathrm{CI})\end{array}$ \\
\hline All & 123 & 95 & 547 & 6564 & 17.4 & $18.7(15.1-23.2)$ \\
\hline $\begin{array}{l}\text { Alpine skiing/ } \\
\text { Snowboarding }\end{array}$ & 51 & 41 & 219 & 2628 & 18.7 & $19.4(13.9-27.0)$ \\
\hline $\begin{array}{l}\text { Cross country } \\
\text { skiing/biathlon }\end{array}$ & 30 & 24 & 149 & 1788 & 16.1 & $16.8(10.9-25.9)$ \\
\hline $\begin{array}{l}\text { Ice sledge } \\
\text { hockey }\end{array}$ & 30 & 18 & 129 & 1548 & 14.0 & $19.4(12.6-29.9)$ \\
\hline $\begin{array}{l}\text { Wheelchair } \\
\text { curling }\end{array}$ & 12 & 12 & 50 & 600 & 24.0 & $20.0(10.1-39.6)$ \\
\hline
\end{tabular}




\section{Incidence of illness by sex and age group}

Table 3 depicts the incidence of illness by sex and age groups. The older category of athletes above 35 years had a higher IR of illness compared to the younger athletes below 25 years (IR of $22.6(95 \%$ CI $16.0 \%-31.9 \%)$ vs. 12.6 (95\% CI $7.9 \%-20.1 \%) \mathrm{p}=0.049)$ with no significant difference reported in IR by sex.

Table 3: Incidence of illnesses by sex and age group (total number of illnesses, number of athletes with an illness, total number of athletes competing, total number of athlete days, proportion of athletes with an illness, illness incidence rates per athlete days)

\begin{tabular}{|c|c|c|c|c|c|c|}
\hline $\begin{array}{l}\text { Sex/Age } \\
\text { group }\end{array}$ & $\begin{array}{l}\text { Total } \\
\text { number of } \\
\text { illnesses }\end{array}$ & $\begin{array}{l}\text { Number } \\
\text { of athletes } \\
\text { with an } \\
\text { illness }\end{array}$ & $\begin{array}{l}\text { Total } \\
\text { number of } \\
\text { athletes } \\
\text { competing }\end{array}$ & $\begin{array}{l}\text { Total } \\
\text { number of } \\
\text { athlete } \\
\text { days }\end{array}$ & $\begin{array}{l}\text { Proportion of } \\
\text { athletes with } \\
\text { an illness }\end{array}$ & $\begin{array}{l}\text { Illness incidence } \\
\text { rate } \\
\text { illnesses/1000 } \\
\text { athlete days } \\
(95 \% \mathrm{CI})\end{array}$ \\
\hline All & 123 & 95 & 547 & 6564 & 17.4 & $18.7(15.1-23.2)$ \\
\hline Female & 28 & 24 & 129 & 1548 & 18.6 & $18.1(11.6-28.3)$ \\
\hline Male & 95 & 71 & 418 & 5016 & 17.0 & $18.9(14.9-24.2)$ \\
\hline \multicolumn{7}{|c|}{ Age 14 to 25} \\
\hline years & 26 & 19 & 172 & 2064 & 11.0 & $12.6(7.9-20.1) *$ \\
\hline \multicolumn{7}{|c|}{ Age 26 to 34} \\
\hline years & 49 & 35 & 198 & 2376 & 17.7 & $20.6(14.7-29.0)$ \\
\hline \multicolumn{7}{|c|}{ Age 35 to 63} \\
\hline years & 48 & 41 & 177 & 2124 & 23.2 & $22.6(16.0-31.9)$ \\
\hline
\end{tabular}

*significantly lower compared to age group 35 to 63 years $(\mathrm{p}=0.049)$

\section{Incidence of illness for each physiological system}

Table 4 shows the physiological systems affected by illness. The most affected system was the respiratory system, with 37 illnesses in 30 athletes, and an IR of 5.6 (95\% CI 3.8\% $8.0 \%$ ). The second most commonly affected system was the eye and adnexa (surrounding tissues) with 18 recorded illnesses and an IR of 2.7 (95\% CI 1.7\%-4.4\%). An IR of 2.4 was recorded for both the digestive system and the skin and subcutaneous system (95\% CI 1.4\% $4.2 \%$ for digestive; $95 \%$ CI $1.3 \%-4.6 \%$ for skin and subcutaneous).

Table 4: Incidence of illness in each physiological system (total number of illnesses, number of athletes with an illness, proportion of athletes with an illness, illness incidence rates per 1000 athlete days)

\begin{tabular}{lllll}
\hline Physiological system & Total number & Number of & Proportion of & Illness \\
\hline
\end{tabular}




\begin{tabular}{lllll}
\hline & of illnesses & $\begin{array}{l}\text { athletes with } \\
\text { an illness }\end{array}$ & $\begin{array}{l}\text { athletes with } \\
\text { an illness }\end{array}$ & $\begin{array}{l}\text { incidence rate } \\
\text { illnesses/1000 } \\
\text { athlete days } \\
\mathbf{( 9 5 \% ~ C I ) ~}\end{array}$ \\
\hline All & 123 & 95 & 17.4 & $18.7(15.1-23.2)$ \\
Respiratory & 37 & 30 & 5.5 & $5.6(3.8-8.0)$ \\
Eye and adnexa & 18 & 17 & 3.1 & $2.7(1.7-4.4)$ \\
Digestive system & 16 & 14 & 2.6 & $2.4(1.4-4.2)$ \\
Skin and subcutaneous & 16 & 13 & 2.4 & $2.4(1.3-4.6)$ \\
Genitourinary & 8 & 8 & 1.5 & $1.2(0.6-2.4)$ \\
Mental and brain & 8 & 8 & 1.5 & $1.2(0.6-2.4)$ \\
\hline
\end{tabular}

\section{The main physiological system affected by illness in each sport category}

In the alpine skiing/snowboarding category, 11 of the reported illnesses (22\%) were digestive illnesses (IR of $4.2(95 \%$ CI 2.2\% - 7.8\%)). In ice sledge hockey, 10 reported illnesses (33\%) were respiratory illnesses (IR of 6.5 (95\% CI 3.2\% - 13.24\%)). For wheelchair curling, 5 of the reported illnesses (42\%) were in the eye and adnexa system (IR of 8.3 (95\% CI $3.3 \%-21.2 \%)$ ). In cross country skiing/biathlon, 16 of the total number of illnesses reported (53\%) were respiratory illnesses (IR of 8.9 (95\% CI of $5.1 \%-15.8 \%)$ ).

\section{Symptomatology of illness}

The diagnosis and frequency of symptoms of the 123 illnesses reported during the Games period are described in Table 5 (supplementary content). The most common symptom of illness were sore throat, followed by nasal congestion and pain.

\section{Time loss as a result of illness}

Of the illnesses reported during the Games period, $21 \%$ of athletes reporting an illness required one or more days of exclusion from training or competition, whilst $79 \%$ of athletes reporting an illness required no time loss from training or competition.

\section{DISCUSSION}

The present study aimed to document the incidence of illness at the Sochi 2014 Winter Paralympic Games in four combined categories of sports. Similar to the study investigating the incidence of injury at the Sochi 2014 Winter Paralympic Games, this study was the first 
to document illnesses per 1000 athlete days at an international Winter Games. Thus, the present study has provided the first reliable baseline data for the incidence of illness at such a competition. There has been limited previous research that has reported illness as a minor variable in papers focused predominantly on injury incidence at international sporting events. However, these studies were also limited by generic definitions of illness and less reliable data collection systems, often relying on athlete self-report and cross-sectional survey data.[1-5]

\section{Higher incidence of illness in Paralympic athletes in a Winter Games setting}

The first important finding of this study was the number of illnesses reported by athletes during the Games period. A total of 123 illnesses were documented in 547 athletes, representing $17.4 \%$ of the total number of athletes attending the Games (IR of 18.7 per 1000 athlete days (95\% CI 15.1\% - 23.2\%). A study investigating able-bodied athletes at the Sochi 2014 Winter Olympic Games reported 249 illnesses in 2780 athletes, representing 8\% of all athletes participating in the study.[14] The incidence of illness recorded during their study was similar to that reported at both the London 2012 Olympic Games and Vancouver 2010 Winter Olympic Games (8\% at the Sochi Games vs. 7\% at both the London and Vancouver Games).[9, 15] This difference between Paralympic and Olympic athletes was also observed at the London 2012 Games, where Paralympic athletes reported twice the rate of illnesses, compared to their able-bodied counterparts (7\% at Olympic Games vs. $14.2 \%$ at Paralympic Games).[6, 15]

The IR reported in the current study (IR of 18.7 (95\% CI 15.1\% - 23.2\%)) in a Winter Games setting was also higher than that recorded in the 2012 London Summer Paralympic Games, where 501 illnesses were recorded in 365 athletes (14.2\% of all athletes, IR of 13.2 (95\% CI $12.2 \%-14.2 \%)$ ). Thus, the findings of the current study provide the first evidence for the difference in illness incidence and proportion between Olympic and Paralympic athletes at international Winter sporting events, as well as a difference in illness incidence between Winter and Summer sporting settings in Paralympic athletes. The possible reasons for high illness incidence in Paralympic athletes compared to Olympic athletes require further investigation. However, the effect of impairment on immune function and higher risk for infection in Paralympic athletes may contribute to rates reported in the current study.[16] Additional factors may include an increased risk of genitourinary infection due to neurogenic bladder and self-catheterisation or use of an indwelling catheter;[17] reduced pulmonary 
function in athletes with higher level neurologic injury such as quadriplegia or quadriparetic cerebral palsy;[18] or the increased age of athletes with impairment competing at the Games.[19]

\section{Incidences and ratios of illness between four sporting categories}

The second important finding of the current study was the similar incidence of illness across the four categories of sports. The highest IR was recorded in wheelchair curling (IR of 20.0 (95\% CI 10.1\% - 39.6\%)) whilst the same IR was reported for two additional sporting categories (alpine skiing/snowboarding, and ice sledge hockey; IR of 19.4 (95\% CI 13.9\% $27.0 \%$ and $95 \%$ CI $12.6 \%$ - 29.9\%, respectively). Interestingly, the ratio of illnesses per athlete was 1.7 for ice sledge hockey and 1.2 for alpine skiing/ snowboarding, despite the same IR, providing insight into the actual rate of illnesses in these athletes. The ratio in wheelchair curling was 1.0 (12 illnesses in 12 athletes), which highlights that the high IR of wheelchair curling is likely a result of low numbers and a somewhat hindered statistical analysis, as opposed to a high number of illnesses in that sport. In the future, comparison of sport-specific data longitudinally across several Winter Paralympic Games will be helpful in increasing statistical power, thus enabling more specific comparisons between sports.

\section{Three most commonly affected physiological systems}

The third important finding of the present study was the distribution of illnesses in various physiological systems. The highest IR was reported in the respiratory system (IR of 5.6 (95\% CI $3.8 \%-8.0 \%)$ ), followed by the eye and adnexa (IR of 2.7 (95\% CI $1.7 \%-4.4 \%$ )) and the digestive system (IR of $2.4(95 \%$ CI 1.4\% - 4.2\%)). Illness in the respiratory system has been reported as consistently higher than illnesses affecting other systems in both Summer and Winter Games settings, as well as in both able-bodied athletes and athletes with impairment. $[6,9,14,14,15]$ The finding in the present study of relatively high rates of illness in the eye and adnexa represents a novel contribution to the literature. Interestingly, a higher number of respiratory illnesses were reported in outdoor endurance events, whilst higher incidence of illnesses in the eye and adnexa system were documented in indoor curling events. This difference in the pattern of illness in physiological systems between the sports is a novel finding and, similar to the findings of the previous paragraph, requires additional research in future longitudinal studies. 


\section{Higher incidence of illness in older athletes}

Finally, there was a significant yet marginally lower IR of illness for athletes in the 14-25 years age category, compared to the other two age categories (Table 3 (95\% CI) p=0.049), indicating that older athletes are possibly more susceptible to illness than younger athletes. As mentioned in the introduction of this paper, this may be due to immune function changes as a result of increased age.[19] The relationship between age, illness and impairment needs to be further explored in future studies.

\section{Limitations of the study}

There were a number of limitations of the current study. Firstly, the definition of illness used in this study is broad and might include the reporting of seemingly trivial symptomatology and also severe life threatening illness. Future studies should address this limitation. Secondly, whilst diverse ocular conditions including conjunctivitis and keratitis were listed as specific diagnoses in some of the illnesses, the final diagnoses were not available for the majority of cases recorded and this constitutes a limitation of the present study. It is however possible that the adverse weather and resultant bad snow conditions, including ultraviolet damage (sun burn and glare) might have contributed to the high incidence of eye and adnexa illnesses reported in the Sochi Winter Games setting.[20] Furthermore, there is a common link between allergic upper respiratory tract infection and rhinoconjunctivitis observed in able-bodied athletes, which may have occurred in the present study.[21] Further detailed investigation is thus required and is planned for future studies at the next edition of the Winter Paralympic Games. Another limitation of the present study was that two electronic sources were used for data collection. It is suggested that this is addressed in future studies of the epidemiology of illness at Paralympic Games. Furthermore, the relatively small total number of illnesses and athletes reporting illness does not allow for complex multivariate analysis in this study. Future longitudinal studies with larger sample sizes might be helpful in the identification of and discussion of risk factors for illnesses in a Winter Paralympic Games setting.

In summary, the incidence of illnesses reported at the Sochi 2014 Winter Paralympic Games was higher than both the London 2012 Summer Paralympic Games, as well as the Sochi 2014 Winter Olympic Games. The current study also revealed similar incidences of illness reported in all sporting categories, although a slightly higher IR was reported in wheelchair curling. Additionally, different illness patterns were observed in different sports. The 
highest rates of illness were reported for the respiratory, eye and adnexa and digestive systems, respectively. Further research is required on the factors associated with eye and adnexa illness at Winter Paralympic sporting events.

\section{ACKNOWLEDGEMENTS}

This study was approved and supported by the IPC. The authors would like to acknowledge and express their gratitude to the hard work of Cris Gomes, Oriol Martinez and NormaAngelica Patino Marques, as well as the support of Sochi Medical Services led by Dr. Alexey Pleskov and all participating NPC Chief Medical Officers. Furthermore, we would like to thank ACER for their generous donation of ACER tablets for the collection of data in the study. 


\section{REFERENCE LIST}

1. D. Taylor and T. Williams, "Sports injuries in athletes with disabilities: wheelchair racing," Paraplegia, vol. 33, no. 5. pp.296-299, May, 1995.

2. B. Kegel and D. Malchow, "Incidence of injuries in amputees playing soccer," Palaestra, vol. 10, no. 2. pp.50-54, 1994.

3. R. Burnham, E. Newell, and E. Steadward, "Sports medicine for the physically disabled: The Canadian team experience at the 1988 Seoul Paralympic Games," Clin.J.Sport Med., vol. 1. pp.193-196, July, 1991.

4. K. J. Richter, S. C. Hyman, C. A. Mushett et al., "Injuries in world class cerebral palsy athletes of the 1998 South Korea Paralympics.," Journal of Osteopathic Sport Medicine, vol. 7. pp.15-18, 1991.

5. M. S. Ferrara and R. W. Davis, "Injuries to elite wheelchair athletes," Paraplegia, vol. 28, no. 5. pp.335-341, June, 1990.

6. M. Schwellnus, W. Derman, E. Jordaan et al., "Factors associated with illness in athletes participating in the London 2012 Paralympic Games: a prospective cohort study involving 49,910 athlete-days," Br.J.Sports Med, vol. 47, no. 7. pp.433-440, May, 2013.

7. M. Schwellnus, W. Derman, T. Page et al., "Illness during the 2010 Super 14 Rugby Union tournament - a prospective study involving 22676 player days," Br.J.Sports Med, vol. 46, no. 7. pp.499-504, June, 2012.

8. J. Dvorak, A. Junge, W. Derman et al., "Injuries and illnesses of football players during the 2010 FIFA World Cup," Br.J.Sports Med, vol. 45, no. 8. pp.626-630, June, 2011.

9. L. Engebretsen, K. Steffen, J. M. Alonso et al., "Sports injuries and illnesses during the Winter Olympic Games 2010," Br.J.Sports Med, vol. 44, no. 11. pp.772-780, Sept., 2010. 
10. P. Van de Vliet, P. Pit-Grosheide, and O. Martinez-Ferrer, "Sport Medicine and Physical Challenge." FIMS Team Physicial Manual. L. Micheli, F. Pigozzi, K. M. Chan et al., eds. vol. 3rd, pp. 216-229. 2013. Routledge.

Ref Type: Book Chapter

11. N. Webborn and d. Van, V, "Paralympic medicine," Lancet, vol. 380, no. 9836. pp.65-71, July, 2012.

12. "International Paralympic Committee." . May 2014. 5-14-2014.

Ref Type: Online Source

13. W. Derman, M. Schwellnus, E. Jordaan et al., "Illness and injury in athletes during the competition period at the London 2012 Paralympic Games: development and implementation of a web-based surveillance system (WEB-IISS) for team medical staff," Br.J.Sports Med, vol. 47, no. 7. pp.420-425, May, 2013.

14. T. Soligard, K. Steffen, D. Palmer-Green et al., "Sports injuries and illnesses in the Sochi 2014 Olympic Winter Games," Br.J.Sports Med, vol. 49, no. 7. pp.441447, Apr., 2015.

15. L. Engebretsen, T. Soligard, K. Steffen et al., "Sports injuries and illnesses during the London Summer Olympic Games 2012," Br.J.Sports Med, vol. 47, no. 7. pp.407-414, May, 2013.

16. B. Brommer, O. Engel, M. A. Kopp et al., "Spinal cord injury-induced immune deficiency syndrome enhances infection susceptibility dependent on lesion level," Brain, vol. 139, no. Pt 3. pp.692-707, Mar., 2016.

17. M. J. McKibben, P. Seed, S. S. Ross et al., "Urinary Tract Infection and Neurogenic Bladder," Urol.Clin.North Am., vol. 42, no. 4. pp.527-536, Nov., 2015.

18. K. Postma, M. W. Post, J. A. Haisma et al., "Impaired respiratory function and associations with health-related quality of life in people with spinal cord injury," Spinal Cord., Feb., 2016. 
19. R. Valiathan, M. Ashman, and D. Asthana, "Effects of Ageing on the Immune System: Infants to Elderly," Scand.J.Immunol., vol. 83, no. 4. pp.255-266, Apr., 2016.

20. S. Willick and J. Lexell, "Stories from Sochi: sun, sea, snow, and salt," PM.R., vol. 6, no. 8 Suppl. pp.S76-S79, Aug., 2014.

21. M. Bonini, C. Gramiccioni, D. Fioretti et al., "Asthma, allergy and the Olympics: a 12-year survey in elite athletes," Curr.Opin.Allergy Clin.Immunol., vol. 15, no. 2. pp.184-192, Apr., 2015. 